\title{
Potential of Power Generation Utilizing Waste Kinetic Energy from Vehicles
}

\author{
Wail Adaileh $^{1}$, Khaled Al-Qdah ${ }^{2}$, Mayyas Mahasneh ${ }^{1}$ \\ ${ }^{1}$ Mechanical Engineering Department, Tafila Technical University, Tafila, Jordan; ${ }^{2}$ Mechanical Engineering Department, Faculty of \\ Engineering (Madinah Munawrah), Taibah University, Medina, KSA. \\ Email: wadaileh@yahoo.com
}

Received January $17^{\text {th }}, 2012$; revised March $6^{\text {th }}, 2012$; accepted March $14^{\text {th }}, 2012$

\begin{abstract}
Energy generation has seen significant development in recent years. This investigation describes a new technique for generating energy from the waste kinetic energy of the vehicles at low speed. A complete description of the system is presented including the general concept, configurations, mechanical design, and electrical system. The system based on the principle of drum rotation due to low movement or transportation of the vehicles driven at low speed at different places such as moles, hotels, universities entrance and fast meals gates. The results show that this new technology could provide an efficient and low cost method of generating electricity from vehicles and the generated electricity has been utilized for different types of applications and mainly for street lighting, domestic uses such as air conditioning, lighting, heating. Some major factors have been studied and practically designed and tested such as there is no possibility to failure or yielding of shaft under loading and the drum is more strength to bending and other forms of stress. It was found through this work that the generated electricity of system and under Jordanian climate conditions can be utilized for electrical and the vehicles waste kinetic energy is one of the renewable sources of energy which can be harnessed to generate electricity. This system depends on the vehicle's weight, when the weight increase the rpm of the drum will increase. As the horizontal vehicle speed is increased the rotational speed of the drum will be increased. It was found that the effective rotational drum speed $(\mathrm{n}=35 \mathrm{rpm})$ at which the system starts to charging. The friction between the tire and the drum increases when the vehicle weight increases. The reported results indicated that we need only about $10 \%$ of vehicle attractive effort to generating a sizable amount of electrical energy. Also, the testing results proven that the minimum effective vehicle's speed is $20 \mathrm{Km} / \mathrm{hr}$, this means that all of the vehicle going over the system can be harnesses to produce the energy. The suggested model will be able to generate energy may be economically feasible to use for a larger applications, and thus helps to reduce the costs of energy production. On the practical side we have been able to produce and store electrical energy using this model at minimum speed of $20 \mathrm{~km} / \mathrm{hr}$, and the system is considered simple to install, inexpensive compared with other sources, safe, and has no bad impacts on the environment. Also, the system can be modified and subjected to upgrading. The system total cost was found to be about US \$900 and this is an extra motivation to use this system.
\end{abstract}

Keywords: Harvesting; Waste Energy; Vehicle; Generator; Kinetic Energy; Electrical Power; Drum

\section{Introduction}

Jordan is relatively poor in conventional energy resources. The long-term security requirement of Jordan is to reduce the dependence on imported oil and natural gas and move towards use of renewable energy sources [1]. Moreover, the extensive fossil fuel exploitation results in atmospheric and environmental pollution and led to some undesirable phenomena represented by global warming, greenhouse effect, climate change, ozone layer depletion, and acid rain. It is therefore unlikely that any future energy scenario for Jordan will not include a significant proportion of its energy to come from renewable sources such as solar and wind energies. Utilization of renewable energy is becoming essential to sustain people's lifestyle, reduce carbon emissions of greenhouse gases and lessen the consumption of limited resources. The current global economic uncertainties and the fluctuation of energy prices are forcing countries and organizations to research and develop more efficient green energy generation methods and many countries are working towards more independence in relation to their energy supplies. Reducing or eliminating the dependency on petroleum of transportation systems is a major element of energy research activities. Certain power generation technologies are not new, such as, internal combustion engines and gas turbines. On the other hand, due to the changes in the utility industry, 
several new technologies are being developed or advanced toward commercialization, such as, fuel cells and photovoltaic. In the past few years, power generation technologies have made a growing number of excited claims that small generators will revolutionize the electricity generation sector.

On this background, the objective of the current research is to draw the attention of decision makers to the advantages of exploiting the energy from a new sources by utilizing the kinetic energy of vehicles at low speed, this speed is available in our cities, Universities, moles, hotels and fast mea restaurants as examples. Harvesting this energy and stored it in specific batteries so it can be used for domestic applications because electrical power systems have been traditionally designed taking energy from high-voltage levels, and distributing it to lower voltage level networks. There are many generation units connected to transmission networks. Besides, distributed generation units, local responsive demands, and storage systems can be operated stand alone or integrated into the electricity grid if the harvested energy is available continuously. In the last decade many countries have started the process of liberalization of their electric systems, opening access to transmission and distribution grids. The electric power system map known as "distributed generation" is related to the use of small generating units installed close to load centers.

Many researchers have been conducted the electricity generation and control from renewable sources, the most available studies is: Essalaimeh et al. [2], carried out an experimental investigation of the using a combination of solar and wind energies as hybrid system for electrical generation under the Jordanian climate conditions. The generated electricity has been utilized for different types of applications and mainly for space heating and cooling. Yilmaz et al. [3], studied an easy method for electrical energy production by solar panels and this method applied to Gaziantep city in Turkey. Dondi et al. [4], reviewed the position of distributed generation (DG, as these small units are called in comparison with central power plants with respect to the installation and interconnection of such units with the classical grid infrastructure. Angel and Bayod-Ru [5], electrical power systems have been traditionally designed taking energy from high-voltage levels, and distributing it to lower voltage level networks. [6] Fayyad and Al-Salaymeh, investigated the issue of connecting renewable energy to traditional electricity grids. The problem originally started to appear when renewable energy generators crave to be connected to traditional grids; due to the facts that renewable energy generation in most cases is not stable and varies from time to time. Naji [7], the potential of utilizing wind and solar Private Distributed Generation (PDG) has been conducted for selected stations in Jordan. Wang et al. [8], used a new unit commitment model which can simulate the interactions among plug-in hybrid electric vehicles, wind power, and demand response. Four plugin hybrid electric vehicles charging scenarios are simulated for the Illinois power system. Zhenyu, 2007 [9], the control of flywheel battery is researched using three phase motor generator. Vector control method is used to control the flywheel battery. Yiew et al. [10], studied the feasibility of using a hybrid plant as com- pared to stand alone solar and wind power plant, the efficiency of solar powered system were studied for further improvement of overall performance. Zeinab et al. [11], discussed the efficient system of sustainable renewable energy for domestic used and its total cost, the study was a collection of the basic solar radiation and wind speed and other requirement data. Yilmaz [12], the possibility of using the renewable energy sources and to find out the using for environmental problems in Turkey was analyzed. Several issues relating to the renewable energy, environment and sustainable development are examined. Chalvatzis [13] examined the progress of the Polish electricity sector throughout the last decades, providing useful information regarding not only the technical generation and distribution infrastructure but also the policies that have been and are currently implemented. Dongmin et al. [14], Based on renewable energy resources system of the village, their work expounds the basic structure and basic equipment of village grid and ac distribution. Based on the operation experience and multiple relevant national standards, this work gives the professional conclusion about quality of power supply, security requirements and equipment's functions, can provide a beneficial reference to national standards of relevant fields. Wang et al. [15], Proposed a new energy control strategy for a distributed power generation system based on renewable. Jim McDonald [16], Presented a new work looks at moves towards active distribution networks. The novel transmission and distribution systems of the future will challenge today's system designs for power systems Saqr and NorMusa [17], they discuss the energy consumption trends in the Malaysian road transport sector, with a special emphasis on the energy losses due to vehicle aerodynamic drag on highways. The novel concept aims at providing a sustainable and green energy source for the lighting of the highway network in the country.

From the previous work it is clear that none of these works conducted the power generation from the waste kinetic energy extracted from the vehicles which is the main aim of this work.

\section{Materials and Method}

When power introduced into the grid, the energy storage acts as a damper and regulator in the electric network [18]. Now, everyone know that a certain amount of en- 
ergy is lost when a car approaches and drives over a speed; in order to harness this energy as its being spent. The method of system design is based on drum installed at the entrance of building such as hotels, moles and other places. When the drum rotates continuously when the vehicles pass over it and the energy can be stored efficiently so that it can be used when it's needed. Some even say that the system actually causes vehicles to use more energy to go over these types of speed bumps; meaning that any electricity created is done so through the vehicle consumed more fuel to achieve the desired result. Aside from specially designed speed bumps that can extract energy from slow-moving what makes this an innovative approach is that it doesn't force drivers or car manufacturers to do any significant changes, such as switching over to electric cars or other fossil fuel alternatives. The system is more efficient to work at a heavy traffic at slow speed.

\subsection{Principle of Work}

Figure 1 shows the schematic diagram of the proposed model. As the tires rotate (4) the vehicle traction effort is transmitted to the drum (3) at the point of contact, which causes the drum to rotate in an opposite direction at a higher rotational speed. Because of the speed ratio between the tire and the drum and the driving pulley (5) rotates with the same rotational speed as the drum speed, using a flat belt (9) the small driven pulley begin to rotate with a higher pulley speed ratio. The second pulley (13) will rotate at the same speed. Then, using a second flat belt (7) the generator pulley (6) will rotate at a higher speeds ratio. This causes the generator (8) to generate an electrical energy which can be stored in battery (14) then will be possible to use this energy for different applications such as street lighting, air conditioning units and other domestic uses.

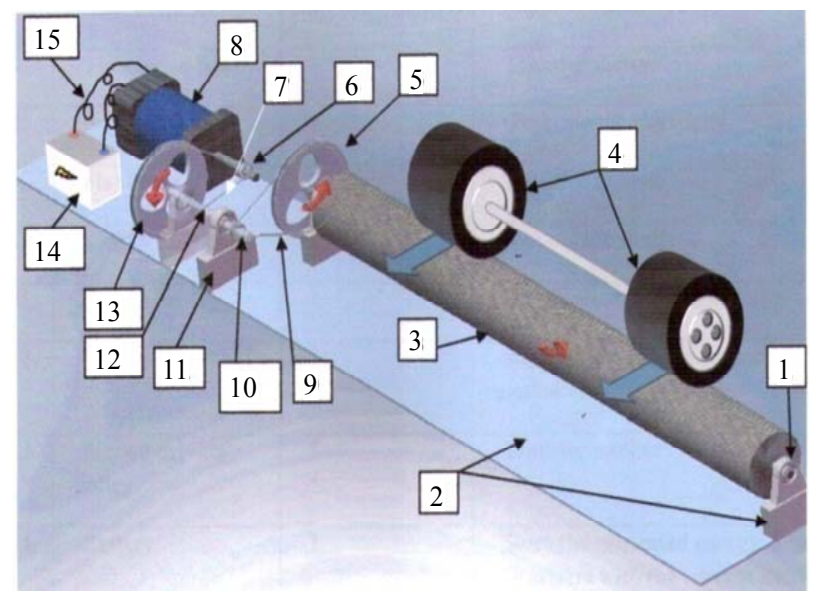

Figure 1. The proposed model designed for this investigation.

\subsection{Theoretical Background and Design Calculations}

Before the system test, it is necessary to examine the proposed design from the strength point of view in order to validate its safe to work under variable load. Table 1 shows all elements of the system, properties of materials, selection of proper material and the manufacturing process on each item, the numerical example illustrated the results for system strength and the load that can be used.

By testing the system using a vehicle type Nissan light truck in the automotive manual workshop at two speeds, the results of test are as below: The vehicle with the following specifications:

$$
M_{\text {total }}=1.3 \times 10^{3} \mathrm{~kg}
$$

where $M_{\text {total }}$ : the total mass of the vehicle in $\mathrm{kg}$.

$T=116 \mathrm{~N} \cdot \mathrm{m}$ (from the vehicle manual)

where $T$ : maximum engine torque.

where:

$$
\begin{gathered}
e_{0}=e_{G} \times e e_{\text {axle }} \\
e_{0}=5 \times 4=20
\end{gathered}
$$

$e_{0}$ : The overall speed ratio in the driving axle;

$e_{G}$ : Speed ratio in the gear $=5$ (vehicle $e_{\text {axle }}$ : speed ratio in the driver axle $=4$ (vehicle manual);

The tire radius: $r=0.33 \mathrm{~m}$ (vehicle manual);

The mechanical efficiency, $\zeta_{\text {mech }}=90 \%$ (vehicle manual);

The driving axis carries $2 / 3$ of total mass;

The coefficient of friction between the tire and the road surface, $f=0.7$.

The load transmitted to driving axis:

$$
W=\frac{2}{3} \times 1.3 \times 10^{3} \times 9.81=8500 \mathrm{~N}
$$

The tractive effort at the contact point as shown in Figure 2

$$
T_{e}=\frac{T_{\text {engine }} \times e_{o} \times \zeta_{\text {mech }}}{r}=\frac{116 \times 20 \times 90}{100 \times 0.33}=6.3 \mathrm{KN}
$$

\subsection{Nominal Power Calculations}

To calculate the nominal horsepower at driving pulley [19]:

$$
H_{n}=T_{e} \times V
$$

where $V$ : pitch line velocity.

$$
\begin{aligned}
& V=\frac{\pi \mathrm{d} n}{60}=\frac{3.14 \times 6 \times 100}{60}=0.19 \mathrm{~m} / \mathrm{s}=62.8 \mathrm{ft} / \mathrm{min} \\
& H_{n}=6.3 \times 10^{3} \mathrm{~N} \times 0.19 \mathrm{~m} / \mathrm{s}=1.198 \mathrm{KW}=1.6 \mathrm{hp}
\end{aligned}
$$

\subsection{Pulleys Calculation}

A leather flat belt was used with center distance of: Figure 3. Pulley design 
Table 1. Elements of the system and material properties.

\begin{tabular}{|c|c|c|c|c|c|}
\hline No & Item & Material & Material properties & Selection of proper material & Manufacturing process \\
\hline 1 & Drum & Steel AISI 1020 & $\begin{array}{l}\text { Hold high stress, } \\
\text { ability for operating, }\end{array}$ & $\begin{array}{l}\text { Cost, width of vehicle, } \\
\text { weight, radius }\end{array}$ & $\begin{array}{l}\text { Turning, wilding, } \\
\text { Balancing }\end{array}$ \\
\hline 2 & Pulleys & Alloy steel & $\begin{array}{l}\text { Light weight, hold stresses, } \\
\text { ability for operating }\end{array}$ & $\begin{array}{l}\text { Cost, radius, weight, } \\
\text { availability }\end{array}$ & Turning, drilling, \\
\hline 3 & Flat Belts & Leather & $\begin{array}{l}\text { Hold speed and load, no } \\
\text { slipping and no noising, low cost }\end{array}$ & $\begin{array}{l}\text { Cost, availability, } \\
\text { distance between pulleys }\end{array}$ & \\
\hline 4 & Bearing & Steel & Hold speed, load, forces, & $\begin{array}{l}\text { Cost, availability, } \\
\text { radius of shaft }\end{array}$ & \\
\hline 5 & Generator & & 12 V DC (L, R) & Cost, availability & \\
\hline 6 & Shaft & Steel & $\begin{array}{l}\text { Holding stress, } \\
\text { ability for operating }\end{array}$ & Cost, availability & Turning, cutting \\
\hline 7 & Base & Steel & $\begin{array}{l}\text { Holding stress, } \\
\text { ability for operating }\end{array}$ & Availability & $\begin{array}{l}\text { Drilling, cutting, } \\
\text { wilding, grinding }\end{array}$ \\
\hline
\end{tabular}

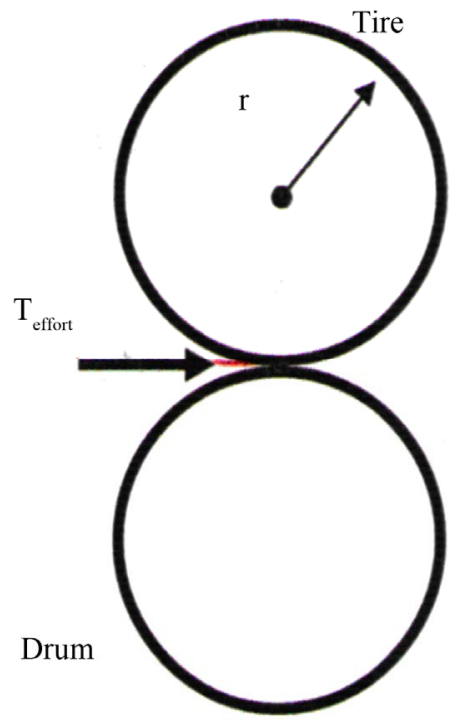

Figure 2. The contact between tire and drum.

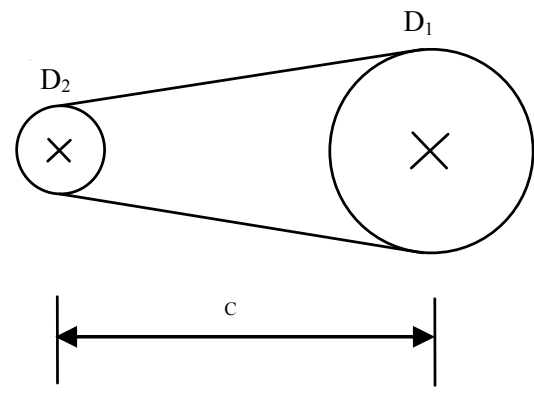

Figure 3. Pulley design.

$\mathrm{C}=66 \mathrm{~cm}=26$ in which transmits a power of:

$$
H_{n}=1.197 \mathrm{~kW}=1.6 \mathrm{hp}
$$

The service factor under different shocks conditions $K_{s}$

$=1.35$,

Factor of safety $n_{s}=2$;

$n_{1}=60 \mathrm{rpm}$;

$D_{1}=10.6 \mathrm{in}$

$D_{2}=2.4$ in.

As shown in Figure 3, where:

$D_{1}$ : Diameter of driving pulley;

$D_{2}$ : Diameter of driven pulley.

From tables available in Shegly [19] the following data are taken:

$t=\frac{33}{64}$ in

$F_{d}=60 \mathrm{Ibf} / \mathrm{in} ;$

$\gamma=0.04 \mathrm{Ibft} / \mathrm{in}^{3}$;

$f=0.4$;

where:

$F_{d}$ : The allowable tension of belt per unit width;

$\gamma$ :Specific weight;

$f$ : Coefficient of friction;

$t$ : The thickness of the belt;

The angle of contact of small pulley [19]:

$$
\begin{aligned}
\theta_{d} & =\pi-2 \sin ^{-1}\left(\frac{10.6-2.4}{2.26}\right) \\
& =3.14-0.3048 \\
& =2.83 \mathrm{rad}=2.83 \times \frac{180}{\pi} \\
& =162^{\circ}
\end{aligned}
$$

The angle of contact of large pulley [19]

$$
\begin{aligned}
\theta_{D} & =\pi+2 \sin ^{-1}\left(\frac{10.6-2.4}{2}\right) \\
& =3.14+0.3048 \\
& =2.44 \mathrm{rad}=3.44 \times \frac{180}{\pi} \\
& =197^{\circ}
\end{aligned}
$$


An open belt connection is used

$$
\begin{aligned}
& L=\sqrt{4 C^{2}-(D-d)^{2}}+\frac{1}{2}\left(D_{D}+d_{d}\right) \\
& L= \sqrt{4.26^{2}-(10.6-2.4)^{2}} \\
&+\frac{1}{2}(3.44 \times 10.6+2.83 \times 2.4) \\
&= 38.34+43.35 \\
&= 81.59 \mathrm{in}=6.8 \mathrm{ft}
\end{aligned}
$$

where $L$ : The length of belt.

The weight $\mathrm{w}$ of $1 \mathrm{ft}$ of belt is given in term of the weight density $\gamma$ as:

$W=12 \gamma b t=12 \times 0.04 \times 7 \times 0.24=0.1 \mathrm{Ibf} / \mathrm{in} ;$

$b=7$ in, $t=0.24$ in.

where:

$b$ : The width of the belt.

$$
\begin{aligned}
T & =\frac{63025 H_{n} \times K_{s} \times n_{d}}{n} \\
& =\frac{63025.1 \times 1.6 \times 1.25 \times 1.1}{60} \\
& =1386 \mathrm{Ibf} / \mathrm{in}
\end{aligned}
$$

where $T$ : The torque of driving pulley.

\subsection{Calculation of Belt Tension}

From [19] the velocity factor $C_{v}=1$, the pulley correc- tion factor $C_{p}=0.7$.

The necessary $\left(F_{1}\right)_{a}-F_{2}$ to transmit the torque $T$

$$
\left(F_{1}\right)_{a}-F_{2}=\frac{2 \times T}{D}=\frac{2 \times 4538}{10.6}=218 \mathrm{Ibf}
$$

where $\left(F_{1}\right)_{a}$ : The allowable largest belt tension.

$$
b\left(F_{1}\right)_{a} C_{p} C_{v}=7 \times 60 \times 0.7=294 \mathrm{Ibf}
$$

The tension at the loose side

$$
F_{2}=\left(F_{1}\right)_{a}-\left[F_{1}-F_{2}\right]=294-218=76 \mathrm{Ibf}
$$

The design horsepower:

$$
H_{d}=H_{n} \times k_{s} \times n_{s}=1.48 \times 1.35 \times 2=4 \mathrm{hp}
$$

\subsection{The Drum Design}

The drum is subjected to bending load of $12.75 \mathrm{KN}$ in xy-plane and the tangential load of $6.3 \mathrm{KN}$ in xz-plane Figure 4, in xy plane shows the sheer force and bending moment diagram, the figure shows that the maximum shear force acted on the shaft is $12.75 \mathrm{KN}$ at the middle of the shaft and the maximum bending moment of 653 $\mathrm{Nm}$ at the center of the shaft.

Figure 5 shows the shear force at xz-plane, the sheer force acted at the center is $6.3 \mathrm{kN}$ and the bending moment at the center of the shaft is $M=323 \mathrm{~N} \cdot \mathrm{m}$.

Figure 5 also illustrates the moment and reactions acted on the shaft

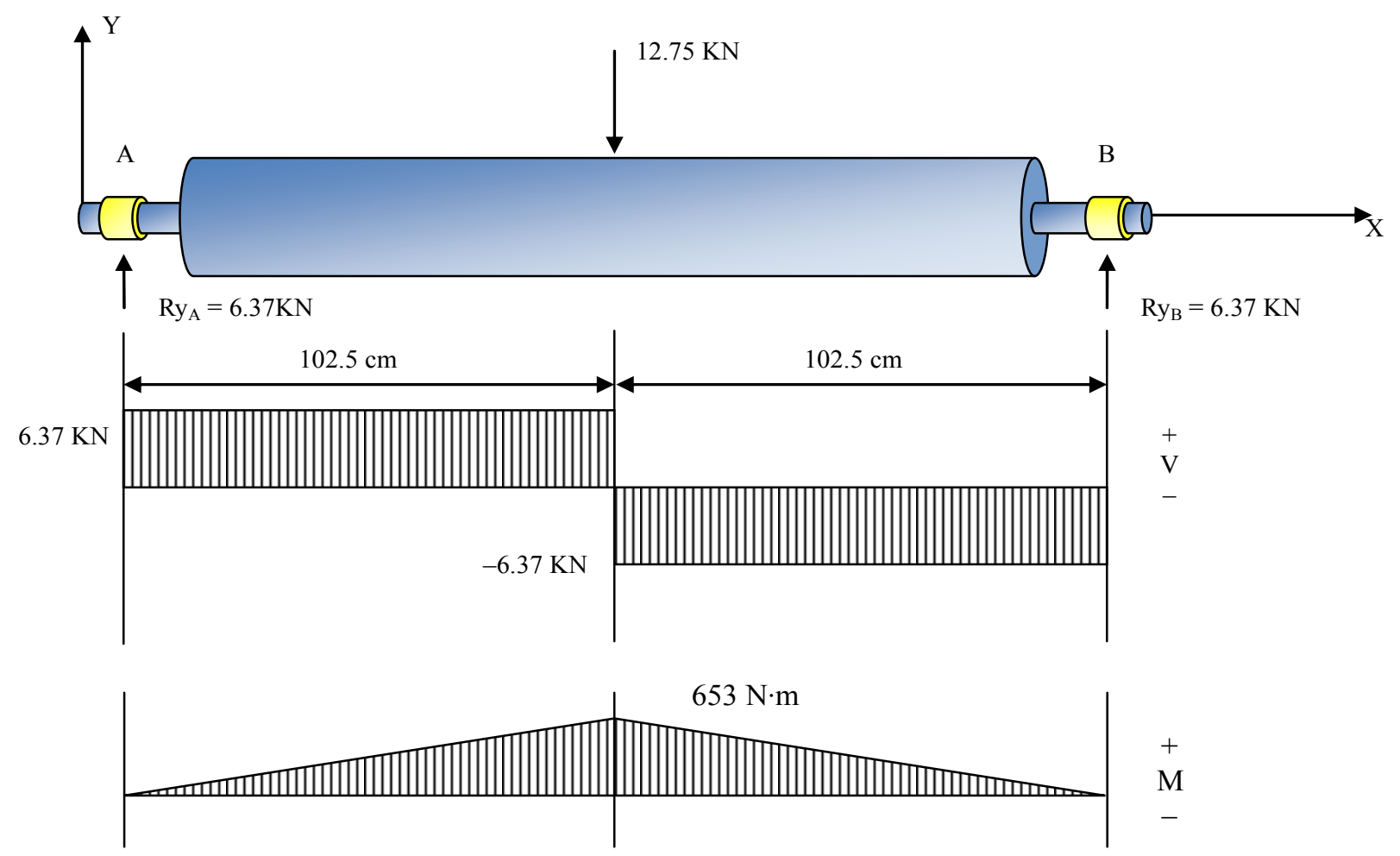

Figure 4. Shear force and bending moment diagram. 


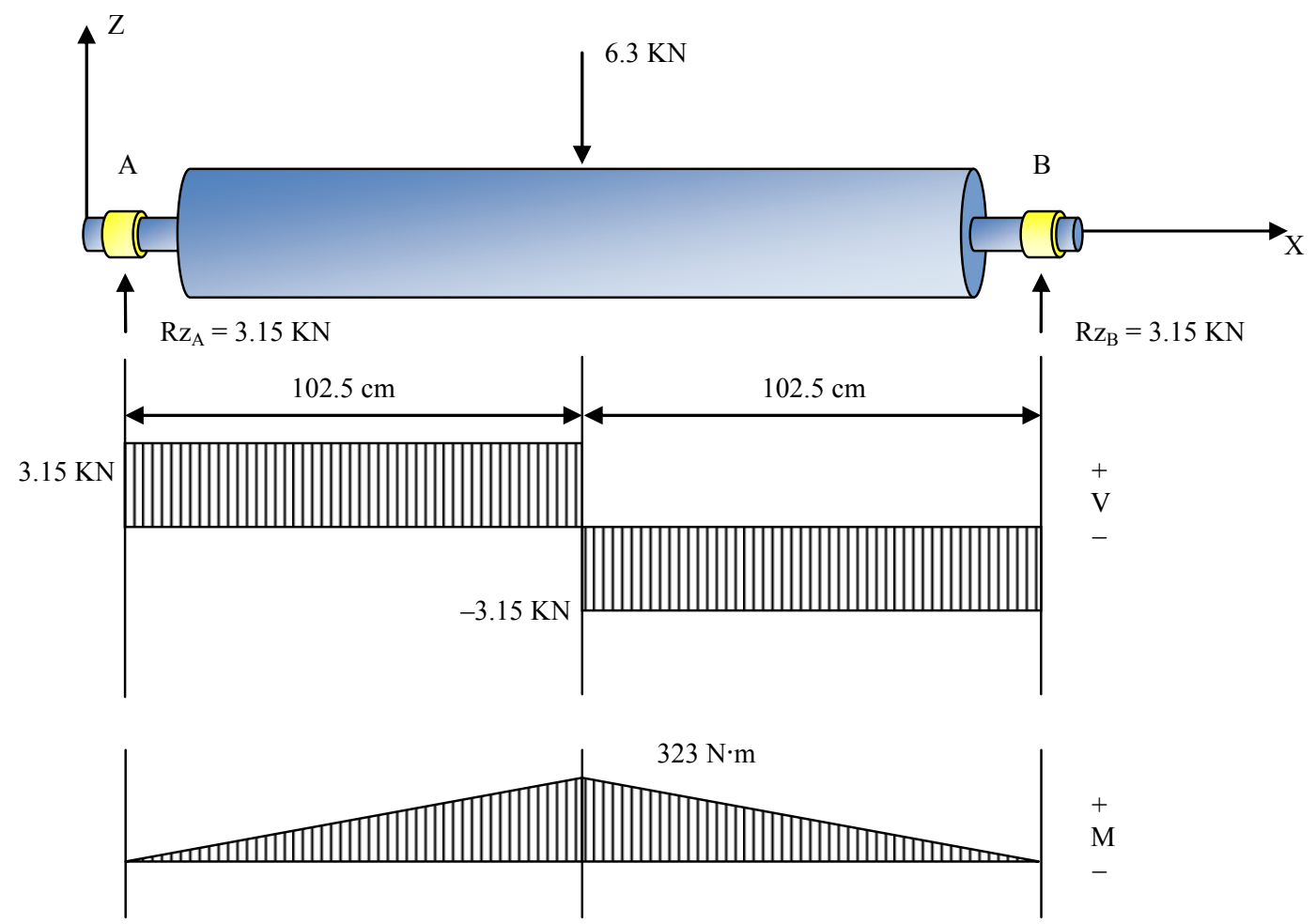

Figure 5. Total moment and reactions for the drum in xz-plane.

$$
\begin{aligned}
& R_{A \text { total }}=\sqrt{R_{y A}^{2}+R_{z A}^{2}}=\sqrt{6.37^{2}+3.15^{2}}=7.1 \mathrm{KN} \\
& R_{A t \mathrm{tal}}=\sqrt{R_{y B}^{2}+R_{z B}^{2}}=\sqrt{6.37^{2}+3.15^{2}}=7.1 \mathrm{KN}
\end{aligned}
$$

The total moment acted on the shaft

$$
M_{\text {total }}=\sqrt{M_{x y}^{2}+M_{x z}^{2}}=\sqrt{653^{2}+323^{2}}=728 \mathrm{~N} \cdot \mathrm{m} \text {. }
$$

\subsection{Calculations of Stress on Shaft}

The drum or shaft subjected to

$$
\begin{gathered}
\sigma_{\text {bending }}=\frac{M C}{I} \\
I=\frac{\pi\left(d_{0}^{4}-d_{i}^{4}\right)}{64}=\frac{\pi\left(22^{4}-19.6^{4}\right)}{64} \\
=4252.6 \mathrm{~cm}^{4}=4.25 \times 10^{-5} \mathrm{~m}^{4} \\
\sigma_{\text {bending }}=\frac{653 \times 0.011}{4.25 \times 10^{-5}}=0.17 \mathrm{MPa} \\
\tau=\frac{\operatorname{Tr}}{\mathrm{J}_{\mathrm{p}}}=\frac{323 \times 0.011}{2 \times 4.25 \times 10^{-5}}=0.042 \mathrm{MPa}
\end{gathered}
$$

where:

$\sigma=\operatorname{stress}(\mathrm{MPa})$

$M$ : Maximum bending moment (MPa);

$C$ : The distance from the outer fiber to the neutral axis;

I: Moment of inertia of shaft cross section;

$\tau$ : The torsion stress.

\subsection{Strength Calculations}

AISI $1020 \mathrm{HR}$ steel used as the material of the drum. With $\mathrm{S}_{\mathrm{y}}=210 \mathrm{MPa}, \mathrm{S}_{\mathrm{ut}}=380 \mathrm{MPa}$.

The alternate component of Von Miss Stress is:

$$
\sigma_{a}^{\prime}=\sqrt{{ }^{\prime 2}+3 \tau_{a}^{2}}=\sqrt{0.17^{2}+3 \times 0.042^{2}}=0.18
$$

The drum strength has a high value comparing with Von Miss Stress; therefore there is no possibility to failure or yielding of shaft under loading.

Figure 6 shows the results of this work. When the generated voltages plot versus speed, it is clear that when the engine operates at the first speed the generated voltage found to be $14.15 \mathrm{~V}$, as the engine operates at the second speed the voltage increase to $14.35 \mathrm{~V}$, with increasing the speed, the voltage increased until it reach steady state value of $14.6 \mathrm{~V}$, this is the maximum volt of generator. The steady state value appears because the action of the voltage regulator in generator, it is necessary to fix the voltage to prevent battery from damaging. High voltage and current cause the battery to become too hot and loose its effectiveness.

\section{Conclusions}

In this work, the converting of kinetic energy into electrical energy was studied. The possibility to produce electrical energy with different ranges by operating this system has been achieved. This system depends on the 


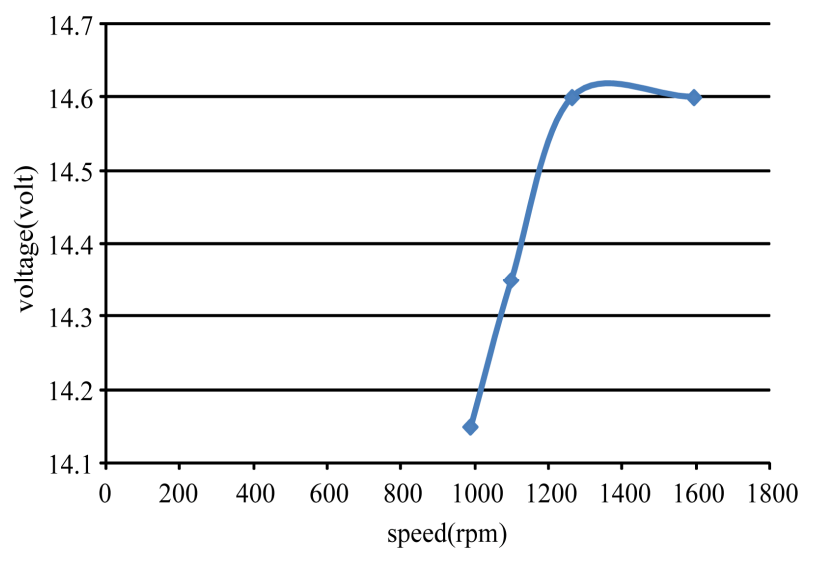

Figure 6. Relation variation of voltage with speed of generator.

vehicle's weight, when the weight increase the rpm of the drum will increase. As the horizontal vehicle speed is increased the rotational speed of the drum will be increased. The effective rotational drum speed is $(n=35$ $\mathrm{rpm}$ ) at which the system starts to charging. The friction between the tire and the drum increases when the vehicle weight increases.

By the calculations it was shown that we need only about $10 \%$ of vehicle attractive effort to generating a sizable amount of electrical energy. Also, the testing results proven that the minimum effective vehicle's speed is 20 $\mathrm{Km} / \mathrm{hr}$, this means that all of the vehicle going over the system can be harnesses to produce the energy.

In the future there will be a large number of small generators connected to the distribution networks, small systems that can be combined with management and storage energy systems in order to improve the operation of distribution systems. From an environmental point of view the system is considered clean, reliable, and secure. If efficient planning and an optimum operation of the grids to which the generation plants are connected are achieved, it will be possible for this model to play a greater role in the future, contributing to energy efficiency improvement, reduction in distribution cost, and power quality improvement. The cost of the total system design, testing and installation reached about 640 JD (US \$900) which is not expensive when it used for a long term.

\section{REFERENCES}

[1] Ministry of Energy and Mineral Resources, "Annual Report," Amman, 2008.

[2] S. Essalaimeh, A. Al-Salaymeh and Y. Abdullat, "Electrical Production for Domestic and Industrial Applications Using," Proceeding to GCREEDER Conference, Amman, 26-28 April 2011.

[3] E. N. Yilmaz, A. Saygin and M. N. Besnili, “An Easy Calculation Method for the Electricity Production by Solar
Panels and Its Applicability in Gaziantep," Journal of Applied Sciences, Vol. 9, No. 21, 2009, pp. 3927-3931. doi:10.3923/jas.2009.3927.3931

[4] P. Dondi, D. Bayoumi, C. Haederli, D. Julian and M. Sute, "Network Integration of Distributed Power Generation," Journal of Power Sources, Vol. 106, No. 1-2, 2002, pp. $1-9$.

[5] A. Angel and J. Bayod-Ru, "Future Development of the Electricity Systems with Distributed Generation," Journal of Energy, Vol. 34, No. 3, 2009, pp. 377-383. doi:10.1016/j.energy.2008.12.008

[6] S. Fayyad and A. Al-Salaymeh, "Renewable Energy Connected to the Grid," Proceeding to GCREEDER Conference, Amman, 26-28 April 2011.

[7] G. J. Naji, K. K. Tahboub and I. S. Jalham, "Small Scale Private Wind and Solar On-Grid Distributed Generation in Jordan: Potential and Economic Feasibility," Proceeding of GCREEDER Conference, Amman, 26-28 April 2011.

[8] J. Wang, L.-Y. Kang and B.-G. Cao, "Neural Network Pid Control of a Distributed Power Generation System Based on Renewable Energy," Journal of Applied Sciences, Vol. 5, No. 10, 2005, pp. 1772-1776. doi:10.3923/jas.2005.1772.1776

[9] Z. Y. Guo, X. P. Mu, Z. F. Bai and B. G. Cao, "Research on the Control of Flywheel Battery," Journal of Applied Sciences, Vol. 7, No. 21, 2007, pp. 3312-3316. doi:10.3923/jas.2007.3312.3316

[10] Y. De An and B. S. M. Singh, "Sustainable Solar-Wind Hybrid Power Plant for Implementation in Malaysia," Journal of Applied Sciences, Vol. 11, No. 7, 2011, pp. 11211128. doi:10.3923/jas.2011.1121.1128

[11] Z. A. M. Elhassan, M. F. M. Zain, K. Sopian and A. Awadalla, "Design of Hybrid Power System of Renewable Energy for Domestic Used in Khartoum," Journal of Applied Sciences, Vol. 11, No. 12, 2011, pp. 2270-2275. doi:10.3923/jas.2011.2270.2275

[12] R. Yilmaz, "Evaluation of Renewable Energy Sources and Sustainable Development Planning of Turkey," Journal of Applied Sciences, Vol. 6, No. 5, 2006, pp. 983-987. doi:10.3923/jas.2006.983.987

[13] K. J. Chalvatzis, "Electricity Generation Development of Eastern Europe: A Carbon Technology Management Case Study for Poland," Renewable and Sustainable Energy Reviews, Vol. 13, No. 6-7, 2009, pp. 1606-1612. doi:10.1016/j.rser.2008.09.019

[14] D. M. Xi, L. J. Hu and X. D. Li, "Power Grid and Alternating Current Distribution Research of Renewable Energy Generate Electric Power's Village System," Energy Procedia, Vol. 12, 2011, pp. 328-334. doi:10.1016/j.egypro.2011.10.044

[15] J. Wang, C. Liu, D. Ton, Y. Zhou, J. Kim and V. Anantray, "Impact of Plug-In Hybrid Electric Vehicles on Power Systems with Demand Response and Wind Power," Energy Policy, Vol. 39, No. 7, 2011, pp. 4016-4021. doi:10.1016/j.enpol.2011.01.042

[16] J. McDonald, "Adaptive Intelligent Power Systems: Active Distribution Networks," Energy Policy, Vol. 36, No. 12, 2008, pp. 4346-4351. 
doi:10.1016/j.enpol.2008.09.038

[17] K. M. Saqr and Md. Nor Musa, "A Perspective of the Malaysian Highway Energy Consumption and Future Power Supply," Energy Policy, Vol. 39, No. 6, 2011, pp. 38733877. doi:10.1016/j.enpol.2011.03.034
[18] G. J. Aubrecht II, "Energy, Physical, Environmental and Social Impact," 3rd Edition, Pearson Prentice Hall, Saddle River, 2006.

[19] J. E. Shegley, "Mechanical Engineering Design," McGraw Hill, Boston, 2008. 